Ergün Can, Z. ve Kutlu Karabıyık, B. (2021). "Forecasting Monero Prices with a Machine Learning Algorithm”, Eskişehir Osmangazi Üniversitesi iiBF Dergisi, 16(3), 651 - 663.

Doi: 10.17153/oguiibf.932839

Başvuru: 04.05.2021 Kabul: 01.06.2021

Araştırma Makalesi/Research Article

\title{
Forecasting Monero Prices with a Machine Learning Algorithm
}

\begin{tabular}{|c|c|}
\hline $\begin{array}{l}\text { Makine Öğrenimi Algoritması ile Monero Fiyatlarının } \\
\text { Tahmin Edilmesi }\end{array}$ & $\begin{array}{l}\text { Forecasting Monero Prices with a Machine Learning } \\
\text { Algorithm }\end{array}$ \\
\hline Öz & Abstract \\
\hline $\begin{array}{l}\text { Literatürde birçok araştırmacının farklı kripto para } \\
\text { birimlerinin değerlerini tahmin etmeye çalıştıkları } \\
\text { gözlemlenmiş, fakat Monero fiyat eğilimlerini analiz eden } \\
\text { çok az çalışmaya rastlanmışır. Monero gizlilik özellikleri } \\
\text { açısından kripto paralar arasında ilk sırada yer almakta } \\
\text { ve talebinin gelecekte artacağı beklenmektedir. Bu } \\
\text { makale, Monero fiyatlarını ve trendlerini tahmin etmek } \\
\text { için PATSOS modelini kullanan ilk çalışma olarak } \\
\text { sınıflandırılabilir. Bulgulara göre PATSOS modeli, çok } \\
\text { düşük bir hata oranıyla gelecekteki Monero fiyatlarını } \\
\text { doğru bir şekilde tahmin etmektedir. Ayrıca, yatırımcılar } \\
\text { PATSOS mekanizması tarafından üretilen tutarlı "al" ve } \\
\text { "sat" sinyallerini kullanarak piyasa oynaklığına direnebilir } \\
\text { ve büyük kayıpları önleyebilirler. }\end{array}$ & $\begin{array}{l}\text { Many researchers have attempted to forecast the values } \\
\text { of different cryptocurrencies, but few studies analyzed } \\
\text { the Monero price trends. Monero ranks first in terms of } \\
\text { privacy features, and its demand is expected to grow in } \\
\text { the future. This paper can be classified as the first to use } \\
\text { the PATSOS model to forecast Monero prices and trends. } \\
\text { According to the findings, the PATSOS model accurately } \\
\text { forecasted future Monero prices with a very low error } \\
\text { rate. Moreover, investors can withstand market volatility } \\
\text { and avoid large losses by using the consistent "buy" and } \\
\text { "sell" signals produced by the PATSOS mechanism. }\end{array}$ \\
\hline $\begin{array}{l}\text { Anahtar Kelimeler: Monero, Fiyat, Trend, ANFIS, } \\
\text { PATSOS, Kripto Paralar }\end{array}$ & $\begin{array}{l}\text { Keywords: Monero, Price, Trend, ANFIS, PATSOS, } \\
\text { Cryptocurrencies }\end{array}$ \\
\hline JEL Kodları: C45, F37, G15 & JEL Codes: C45, F37, G15 \\
\hline \multicolumn{2}{|c|}{$\begin{array}{l}\text { Araştırma ve } \\
\text { Yayın Etiği } \\
\text { Beyanı }\end{array}$} \\
\hline Yazar 1'in makaleye katkısı \%50, Yazar 2'nin mak & eye katkısı \%50'dir. \\
\hline Yazarlar açısından ya da üçüncü taraflar açısında & çalışmadan kaynaklı çıkar çatışması bulunmamaktadır. \\
\hline
\end{tabular}

\footnotetext{
1 PhD- Research Assistant, Aydın Adnan Menderes University, Söke Faculty of Business, International Trade and Business, zeliha.can@adu.edu.tr

2 PhD- Research Assistant, Aydın Adnan Menderes University, Söke Faculty of Business, Management Information Systems, busra.kutlu@adu.edu.tr
} 


\section{Introduction}

With the exponential advancement in technology, the industry has evolved in many ways. The use of fast and reliable information technologies has expanded as a result of Industry 4.0, a new industrial revolution. People often need quick and reliable mechanisms for financial transactions such as purchasing goods and services, making investments and transferring money. The digital currency Bitcoin and the blockchain system have emerged as a step in this direction. Bitcoin was founded by an anonymous name or organization named Satoshi Nakamoto in 2009. It is a digital currency that is transacted on the internet and its transactions are recorded by a decentralized ledger called the blockchain. Apart from having a very high liquidity ratio and low exchange rates, the most significant aspect that separates digital currencies like Bitcoin from fiat currencies is that they are not generated by countries and do not behave following any country's laws. Bitcoin, as mentioned in Satoshi Nakamoto's original paper, allows two parties to interact with each other without the use of a third party (Nakamoto, 2009). This makes Bitcoin transactions anonymous, inexpensive, and rapid (Chen et al., 2021).

Almost 4000 alternative cryptocurrencies, such as Ethereum and Ripple, developed after the invention of Bitcoin (Pintelas et al., 2020). The estimated market capitalization of cryptocurrencies has now surpassed the hundreds of billions of dollars level. Initially, cryptocurrencies were only seen as a way of exchanging currency, but they have recently become a good investing opportunity (Jay et al., 2020). As a result, curiosity in cryptocurrencies has exploded in the past few years, prompting researchers and investors to inquire regarding their prices. Cryptocurrency prices are influenced by a variety of variables, including sentiments, financial markets, regulatory issues, and market trends, which together make their prices unstable and volatile (Patel et al., 2020). Investors and researchers have spent a lot of time trying to figure out whether cryptocurrency prices and movements are predictable.

Traditional time series models such as ARIMA, ARCH, and GARCH are used to forecast time series, but they are argued to be insufficient in forecasting cryptocurrencies due to their limitations in capturing nonlinear dynamics (Altan et al., 2019; Pintelas et al., 2020; Patel et al., 2020). Since most cryptocurrencies have nonlinear, erratic, and volatile patterns, many studies used numerous machine learning algorithms to forecast the values of cryptocurrencies. Machine learning algorithms can capture nonlinear relationships without relying on conventional hypotheses, resulting in more reliable cryptocurrency forecasting performance (Altan et al., 2019; Pintelas et al., 2020). The majority of these studies focused on the most widely used cryptocurrencies, such as Bitcoin, Ethereum, and Ripple (i.e., McNally et al., 2018; Pintelas et al., 2020; Poongodi et al., 2020). However, there are some other cryptocurrencies, such as Monero, that are preferred by many investors.

Monero was introduced in 2014 and its main aim is to enable transactions to be conducted privately and anonymously. Since blockchains are transparent, it is also easy to trace transfers back to their original source and each Bitcoin in circulation has a unique serial number, allowing cryptocurrency used to be tracked. For Monero, on the other hand, senders, receivers, and the sum of crypto being exchanged are all hidden by default. Furthermore, when cryptocurrencies are ranked according to their privacy features on the 
coinmarketcap website, Monero is at the top ${ }^{3}$. It is also classified among the top 12 liquid cryptocurrencies ${ }^{4}$, according to Akyildirim et al. (2021). Moreover, Patel et al. (2021) emphasized that the demand for Monero is expected to rise in the future due to its unique features.

This research aims to use a machine learning model to forecast Monero prices and patterns. To the best of the authors' knowledge, no research uses the PATSOS approach to forecast Monero prices and dynamics. To fill this gap in the literature, this paper is the first to use the PATSOS model to predict Monero prices and trends, and it is hoped that the results will assist investors in evaluating their investment decisions.

The rest of the paper is structured as follows: the second section summarizes the related literature, the third section explains the methodological framework, the fourth section forecasts the Monero prices after the data is described, the fifth section presents the PATSOS results, and the final section concludes the paper.

\section{Literature Review}

Many studies have concentrated on predicting cryptocurrency values using different approaches, but machine learning algorithms are commonly preferred because of digital currencies' nonlinear structure. Since Bitcoin is the most popular cryptocurrency on the market, these studies generally focused on forecasting its movements and values by using several machine learning techniques. Besides, few researchers also analyzed the predictability of some other digital currencies (such as Ethereum, Ripple, and Litecoin).

McNally et al. (2018) used Recurrent Neural Network (RNN) and Long Short-Term Memory (LSTM) methods in predicting Bitcoin prices, and they found these approaches outperformed the ARIMA, which is a conventional time series model. Similarly, Ji et al. (2019) contrasted LSTM with a deep neural network (DNN), a convolutional neural network, a deep residual networks models, as well as their combinations, and concluded that the LSTM model outperformed the others. Moreover, Lahmiri and Bekiros (2019) used LSTM to forecast Bitcoin, Digital Cash, and Ripple and demonstrated that LSTM is an effective model for forecasting these cryptocurrencies. Patel et al. (2020) used Gate Recurrent Unit (GRU) based hybrid approaches in conjunction with LSTM to predict Litecoin and Monero values, concluding that they are effective techniques. On the other hand, Pintelas et al. (2020) compared LSTM to Bidirectional Long Short-Term Memory (BLSTM) and Convolutional Neural Networks (CNN) for Bitcoin, Ethereum, and Ripple value prediction, and claimed that none of these models are efficient. Furthermore, a novel hybrid model is suggested by Altan et al. (2019) based on the LSTM and empirical wavelet transform (EWT) techniques, which are found to be effective in forecasting the values of Bitcoin, Ripple, Digital Cash, and Litecoin.

Karasu et al. (2018) and Aggarwal et al. (2020) applied a Support Vector Machine (SVM) learning algorithm for the Bitcoin price prediction. Karasu et al. (2018) compared this approach to Linear Regression and revealed that the SVM model performs better in terms of forecasting. Also, the SVM model prediction accuracy is high for the short, medium, and long terms, according to Aggarwal et al. (2020). Like Karasu et al. (2018), Poongodi et al. (2020) used both SVM and Linear Regression models to forecast Ethereum prices and confirmed that

\footnotetext{
${ }^{3}$ https://coinmarketcap.com/

${ }^{4}$ Liquidity was described by Akyildirim, et al. (2021) as cryptocurrencies of less than $1 \%$ non-trading periods over all time intervals.
} 
the SVM model provides higher accuracy. On the other hand, to forecast the price of Bitcoin, Liu et al. (2021) compared the Stacked Denoising Autoencoders (SDAE) approach to Back Propagation Neural Network (BPNN) and SVM techniques. According to their findings, SDAE is found to have a better performance than BPNN and SVM. Furthermore, Akyildirim et al. (2021) examined the predictability of the most liquid twelve cryptocurrencies' returns by using SVM, logistic regression, artificial neural networks (ANN), and random forests classification algorithms. They concluded that, while all machine learning techniques are effective at prediction, SVM is the most effective.

ANN is another commonly used machine learning method. Nakano et al. (2018) used ANN to assess the trading performance of Bitcoin, and they discovered that this method improves Bitcoin's performance, particularly during periods of downward trending. Moreover, Kristjanpoller and Minutolo (2018) developed a hybrid model based on ANN and Generalized Autoregressive Conditional Heteroscedasticity (GARCH) to forecast Bitcoin price volatility. Similarly, Jay et al. (2020) suggested a stochastic neural network model for Bitcoin, Ethereum, and Litecoin price prediction, which is found to have strong forecasting efficiency.

Furthermore, Chowdhury et al. (2020) used the ensemble learning system, gradient boosted trees model, neural net model, K-nearest Neighbor (K-NN) model to predict the close price of cci30 and nine cryptocurrencies constituents, and all of the models performed well in forecasting. The Light Gradient Boosting Machine (LightGBM) model was also used by Sun et al. (2020) to forecast 42 primary cryptocurrencies. The conclusion is that LightGBM is an important way to direct investors in building a suitable cryptocurrency portfolio.

Finally, Atsalakis et al. (2019) suggested PATSOS, a neuro-fuzzy paradigm for predicting Bitcoin values. When the PATSOS model is compared to an ANN and a hybrid ANFIS model for forecasting Bitcoin prices, it is discovered that the proposed model is more effective. They also used the PATSOS model to predict the prices of Ethereum, Litecoin, and Ripple for a robustness comparison and got similar results. Based on the findings of Atsalakis et al. (2019), in the current study PATSOS model is preferred to forecast the Monero prices and trends.

\section{Methodological Framework}

In this section, the theoretical foundations of the Adaptive Neuro-Fuzzy Inference System (ANFIS) model and Neuro-Fuzzy Controller Forecasting System (PATSOS) model that has two ANFIS sub-systems in the closed-loop feedback mechanism are described.

\subsection{Adaptive Neuro-Fuzzy Inference System (ANFIS)}

The Adaptive Neuro-Fuzzy Inference System (ANFIS) model which is proposed by Jang (1993) is one of the neural fuzzy approaches that combine the learning ability of neural networks and fuzzy logic models' ability to ensure decision making like humans and providing expert knowledge.

ANFIS model is based on the determination of the appropriate fuzzy rule set using a specific input-output data set and the systematic adjustment of system parameters through an adaptive network structure. In the figure below, a first order Sugeno-type ANFIS structure that has two inputs are pointed out. 
Figure 1: ANFIS Structure

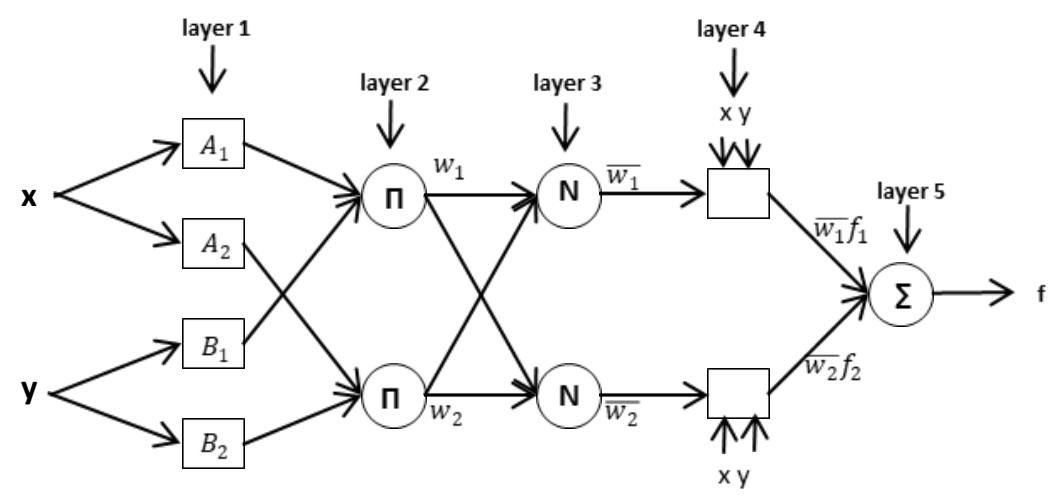

Kaynak: (Jang, 1993: 668)

The ANFIS model has five layers of architecture. All layers are indicated below in detail (Yücel and Güneri, 2010; Urfalıoğlu and Tanrıverdi, 2018).

Layer 1: It is the fuzzification layer. The outputs of this layer are fuzzy membership degrees of inputs. The membership function gives the degree of how much $x$ meets $A$.

$$
\mathrm{o}_{\mathrm{i}}^{1}=\mu_{\mathrm{A}_{\mathrm{i}}}(\mathrm{x})
$$

Layer 2: It is the rule layer. In this section, each circle-shaped node (П) multiplies the incoming signals and subtracts the value. Each node output shows the firing strength of each rule.

$$
\mathrm{o}_{\mathrm{i}}^{2}=\mathrm{w}_{\mathrm{i}}=\mu_{\mathrm{A}_{\mathrm{i}}}(\mathrm{x}) \times \mu_{\mathrm{B}_{\mathrm{i}}}(\mathrm{x}), \mathrm{i}=1,2
$$

Layer 3: It is the normalization (N) layer. The outputs of this layer are qualified as normalized firing strength.

$$
o_{i}^{3}=\overline{w_{l}}=\frac{w_{i}}{w_{1}+w_{2}}, i=1,2
$$

Layer 4: It is the defuzzification layer. While $\overline{w_{1}}$ is the output of Layer $3,\left\{p_{i}, q_{i}, r_{i}\right\}$ are qualified as parameters.

$$
o_{i}^{4}=\bar{w}_{l} f_{i}=\bar{w}_{l}\left(p_{i} x+q_{i} y+r_{i}\right), i=1,2
$$

Layer 5: It is the summation layer. A single node in this layer $(\Sigma)$ calculates an output by summing all incoming signals.

$$
o_{i}^{5}=\sum_{i} \bar{w}_{l} f_{i}=\frac{\sum_{i} w_{i} f_{i}}{\sum_{i} w_{i}}, i=1,2
$$

\subsection{The Neuro-Fuzzy Controller Forecasting System (PATSOS)}

In this study, the Neuro-Fuzzy Controller Forecasting System (PATSOS) method will be used as the main approach for forecasting cryptocurrency price and trend named Monero. This method is suggested by Atsalakis and Valavanis (2009) for the first time to predict stock prices. Afterward, it is widely used in literature to forecast energy's exports (Atsalakis et al., 2015), carbon prices (Atsalakis, 2016), stock trend (Atsalakis et al., 2016a), commodities' price trend (Atsalakis et al., 2016b) and bitcoin prices (Atsalakis et al., 2019). In this study PATSOS method is used for the first time to forecast the Monero prices. 
The PATSOS model also does not require any prior information about the input, output data, and their existing relations. Moreover, it can handle nonlinear data. Finally, it produces clear, understandable, and interpretable outputs via "if-then" rules. These operations can occur approximately in one minute. These features both imply to usefulness and easefulness of the PATSOS model.

PATSOS model includes two ANFIS sub-systems named CON-ANFIS and PR-ANFIS. While the CON-ANFIS sub-system forms inverse learning, the PR-ANFIS sub-system models the forecasting process. Figure 2 presents the PATSOS forecasting system during the training stage.

Figure 2: PATSOS Forecasting System during the Training Phase

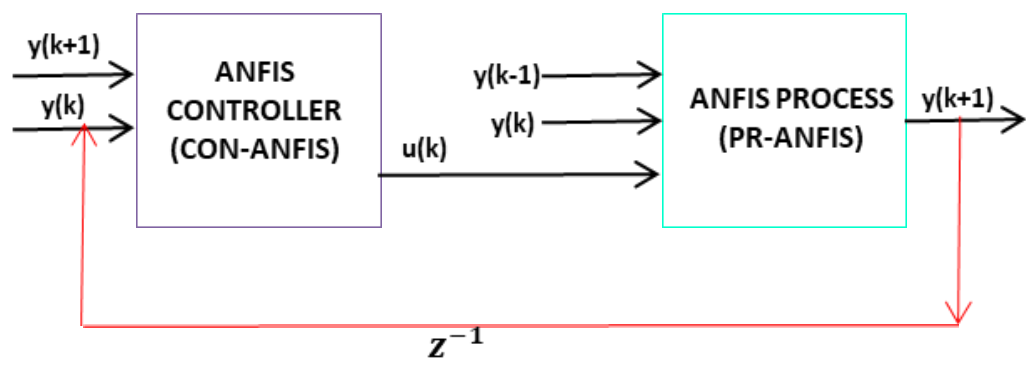

Kaynak: (Atsalakis, 2019: 774)

\subsubsection{Training the CON-ANFIS Controller}

The PATSOS model has two separate ANFIS sub-systems named CON-ANFIS and PR-ANFIS respectively that form a closed-loop feedback system as indicated in Figure 2. The first of them, named CON-ANFIS, helps to realize the inverse learning of the system and constitutes control signals for the PR-ANFIS model that forecasts the following days' Monero price trend. These signals show a change in the information that the system produced. The dynamic structure of the system can easily handle obscurities and sudden disturbances. Therefore, it can be deduced that control signals are affected by the perceptions about market qualifications, past prices, and so on. All learning processes occur by offline techniques. Equations below are realized for the ANFIS controller:

$$
\begin{aligned}
& y(k+1)=f(y(k), u(k)) \\
& u(k)=g(y(k))
\end{aligned}
$$

where $y(k)$ represents the Monero price at time $k$ (current price), $y(k+1)$ indicates the Monero price at time $k+1$, and $u(k)$ is the control signal at time $k$. On CON-ANFIS training model, two inputs $[\mathrm{y}(\mathrm{k})$ and $\mathrm{y}(\mathrm{k}+1)]$ and one output $[\mathrm{u}(\mathrm{k})]$ are provided. Then, the control signal $u(k)$ is operated as an input variable on the PR-ANFIS model to determine the following days' trend $y(k+1)$. Throughout the training phase, the control signal $u(k)$ remains positive and can be calculated as below:

$$
\mathrm{u}(\mathrm{k})=\sqrt{(\mathrm{y}(\mathrm{k})-\mathrm{y}(\mathrm{k}+1))^{2}}
$$

Thereafter many trial and error processes, for each input four (4) Gaussian membership functions (linguistic terms), are chosen: very small, small, big, and very big. When combining the two inputs with the four membership functions, $2^{4}=16$ rules are produced. After all, one 
of the rules can be pointed as the following. If $y(k+1)$ is small and $y(k)$ is small then $u(k)$ is $f_{1}=p_{1} . y(k+1)+q_{1} . y(k)+r_{1}$, where $\left\{p_{i}, q_{i}, r_{i}\right\}$ is parameter set which is determined during the learning phase.

\subsubsection{Training the PR-ANFIS Process}

As stated in the previous sections, the PATSOS model constitutes two ANFIS sub-systems. The first of them is called CON-ANFIS and the second one is referred to as PR-ANFIS. PR-ANFIS models the Monero price forecasting process along with control signals that CON-ANFIS produced and the historical Monero price data. In the end, the PR-ANFIS is trained to constitute accurate forecasts that are one step ahead of the process output (Atsalakis, 2016: 10).

The price of Monero fluctuates in a nonlinear manner; hence it is essential to use an effective identification method. PR-ANFIS succeeds in identification because it is heavily dependent on measured data.

PR-ANFIS process model forecasts the following days' Monero price trend. On PRE-ANFIS training model, three inputs $[\mathrm{y}(\mathrm{k}-1), \mathrm{y}(\mathrm{k})$ and $\mathrm{u}(\mathrm{k})]$ and one output $[\mathrm{y}(\mathrm{k}+1)]$ are provided. Where $y(k-1)$ points to the Monero price at time $k-1, y(k)$ points to the Monero price at time $k$ (current price), $u(k)$ implies to control signal at time $k$ and $y(k+1)$ is Monero price at time $k+1$.

Thereafter many trial and error processes, for each input four (4) Gaussian membership functions (linguistic terms), are chosen: very small, small, big, and very big. When combining the three inputs with the four membership functions, $3^{4}=81$ rules are produced. After all, one of the rules can be pointed as the following. If $y(k-1)$ is small and $y(k)$ is small and then $u(k)$ is small, $f_{1}=p_{1} \cdot y(k-1)+q_{1} \cdot y(k)+s_{1} \cdot u(k)+r_{1}$, where $\left\{p_{i}, q_{i}, s_{i}, r_{i}\right\}$ is parameter set which is determined during the learning phase.

Norgaard, Ravnm \& Poulsen (2003) claim that the following days' value $y(k+1)$, the input of CON-ANFIS in this study, is not known during the evaluation. Therefore, the $y d(k+1)$ variable which is the moving average of the last three days must be used instead of the $y(k+1)$ variable. " $y d$ " concept implies to desired (d) y function. The equations below show the related calculations.

$$
\operatorname{SMA}(\mathrm{k})=\frac{\text { Sum of close price (day k,day } \mathrm{k}-1, \text { day } \mathrm{k}-2)}{3}
$$

Moving average rate $=\frac{\mathrm{SMA}(\mathrm{k})-\mathrm{SMA}(\mathrm{k}-1)}{\operatorname{SMA}(\mathrm{k}-1)}$

As a result, the final two inputs in the CON-ANFIS training process (ANFIS controller) are $y d(k+1)$ and $y(k)$ variables. The CON-ANFIS produces an output $u(k)$ variable which leads PRANFIS to forecast price at time $y(k+1)$ (Atsalakis and Valavanis, 2009). 


\section{Forecasting Monero Prices}

In this section, firstly the data is explained in detail. Afterward, a forecasting performance measure (RMSE) is introduced for evaluating the goodness of the forecast model.

\subsection{Data Description}

In this paper, the trend of the prices is forecasted using daily historical time series data of Monero closing prices. The data are obtained from 2286 observations which are between January 2, 2015, and April 6, 2021 periods. All the data used were obtained from "coinmarketcap.com". In our analysis, the transaction fees of Monero are neglected for maintaining the easiness of the model.

Firstly, the data are divided into two parts as training and validating. When the training error rate obtained very small and oppositely the testing error rate observed as high, which can point out to the memorizing characterizing of the model. To avoid that, both error rates should be investigated in detail. If there is no big difference between them, the chosen model can be selected conveniently. In plenty of studies, the datasets generally divided like 50:50, $60: 40,70: 30,80: 20$, or 90:10 based on convenience. In the machine learning literature, 90:10 ratios are pointed as appropriate solutions respectively for training and testing (i.e., Guiu et al., 1999; Oppenheim and Shani, 2017). Since there are many observations in the dataset, $90 \%$ training sample is seemed sufficient and 90:10 ratios are chosen.

Hence, $90 \%$ of the dataset (2056) for training and $10 \%$ of the dataset (230) for validating are used. Both CON-ANFIS and PR-ANFIS models are trained using the training set and their forecasting ability is evaluated by utilizing the validation set. It should also be emphasized that the validation dataset is from a future period that is not known in the present moment. Therefore, it creates a robust test for understanding the forecasting capability of the model.

\subsection{Forecasting Performance Measure}

In this study, the assessment of PATSOS forecast model performance is carried out via Root Mean Square Error (RMSE) measure. RMSE measure intends to determine differences between forecasts provided by the PATSOS model and the real-world results (i.e. actual outcomes). The mathematical formula takes place below:

$$
\text { Root Mean Square Error RMSE }=\sqrt{\frac{\sum_{\mathrm{t}=1}^{\mathrm{N}} \mathrm{e}_{\mathrm{t}}^{2}}{\mathrm{~N}}}
$$




\section{PATSOS Neuro-Fuzzy Controller Forecasting Results}

First of all, for realizing analysis the epoch number that minimizes RMSE error value is needed to find. After trial-and-error processes, it is seen that when there are 20 training epochs, there is convergence to the RMSE curve. This implies that after 20 epochs, any following training epoch up to 2000 does not upgrade the RMSE value. These findings are observed to be valid for the PR-ANFIS process as well.

Figure 3: Post-Training Mf Shapes of CON-ANFIS

a) Controller Final Mf's on y(k)

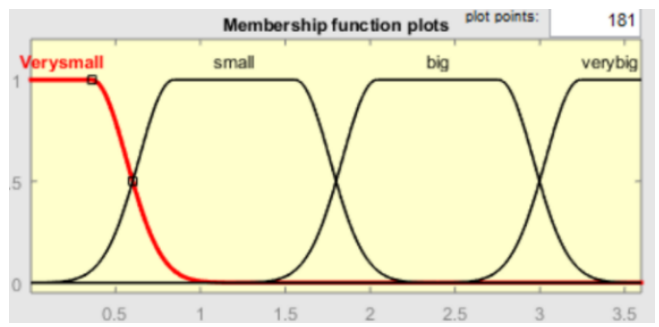

b) Controller Final Mf's on $y(k+1)$

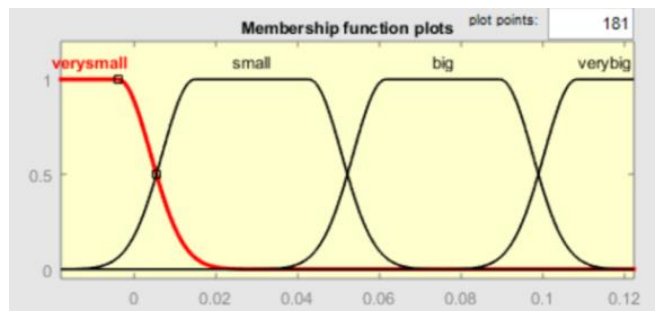

Post-training membership functions (mf) graphs of two inputs in CON-ANFIS are displayed in Figure 3. Next, in Table 1 the details of PATSOS subsystems are demonstrated. It should be noted that all the parameters chosen are the optimal options for the analysis.

Table 1: Parameter Configuration of the CON-ANFIS and PR-ANFIS

\begin{tabular}{ccc}
\hline Specifications & CON-ANFIS & PR-ANFIS \\
\hline Inference mechanism type & Sugeno & Sugeno \\
Number of inputs & 2 & 3 \\
1st input & $y(k)$ & $y(k-1)$ \\
2 nd input & $y(k+1)$ & $y(k)$ \\
3rd input & - & $u(k)$ \\
Outputs & 1 & 1 \\
Output & $u(k)+1)$ \\
And method & Product & Product \\
Or method & Max & Max \\
Imp. Method & Product & Product \\
Agg. Method & Max & Max \\
Defuzz. Method & Wtaver & Wtaver \\
Number of Rules & 16 & 81 \\
Type of MFs & Gauss2mf & Gauss $2 \mathrm{mf}$ \\
Number for training data & 2056 & 2056 \\
Number for evaluation data & 230 & 230 \\
\hline
\end{tabular}


With the aid of a trial-and-error process, the accurate numbers and types of membership functions are selected. Afterward, RMSE statistical scale is used for measuring the error rate of testing data (230 observations). According to the results, the gauss 2 membership function (mf) gave the best performance error of PATSOS. In other saying, the Gaussian $2 \mathrm{mf}$ acquires the lowest RMSE value which is "0,00305". Same membership functions operated both for CON-ANFIS and PR-ANFIS.

Through PATSOS analysis results, both Monero values and trends are detected easily. In Figure 4 actual and estimated prices are demonstrated in detail. On the graph, while the blue dots imply actual prices red asterisks indicate estimated values. Asterisks and dots mostly stand close and move together. So, it should be easefully said that the error rate of estimation is small and the developed PATSOS model may simulate the short-run tendency of Monero prices. In light of such information, the PATSOS model may be described as a very useful tool for cryptocurrency investors who need extrinsic assistance.

Figure 4: PATSOS Forecasts versus Actual Prices for 230 out-of-Sample Prices

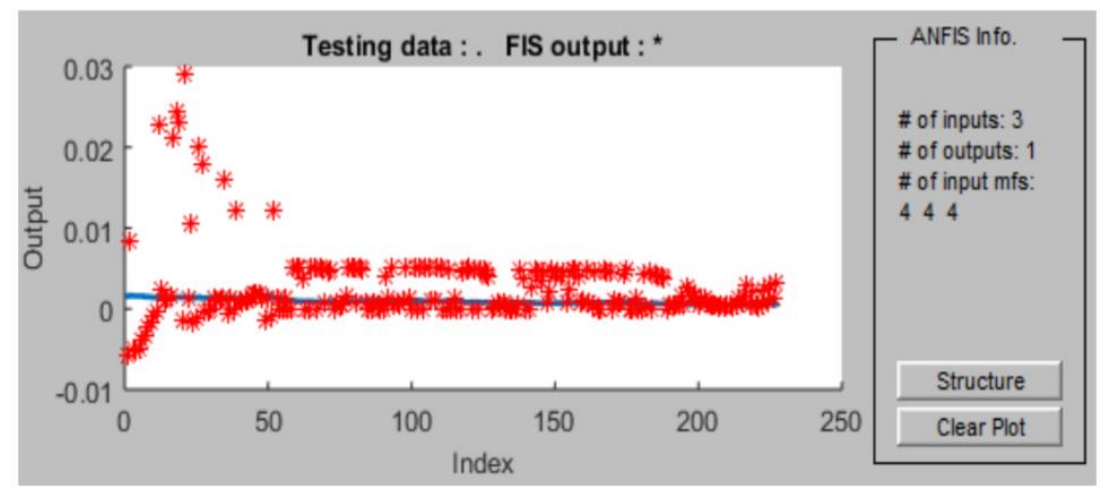

In most analyses, it is enough to indicate the RMSE error is small. But in this study, we will also show that the PATSOS model accurately forecasts the way of change of the future Monero prices. That kind of accuracy is called as "hit rate" and formulated as below:

Hit rate $=\frac{\mathrm{h}}{\mathrm{n}}$

Where the " $\mathrm{h}$ " letter indicates the number of right forecasts of the Monero trend, and the " $n$ " letter implies the number of total tests (230 observations).

At the end of the day, the PATSOS model generates a "buy" sign if it forecasts that the closing price of Monero currency of the following day will be higher than the closing price of the current day. On the contrary, it also generates a "sell" sign if it forecasts that the closing price of Monero currency of the following day will be smaller than the closing price of the current day. These actions can be completed with the PATSOS method less than in a minute.

When the "buy" sign is seen, the Monero assets must be bought and when the "sell" sign is seen, the Monero assets must be sold by the cryptocurrency investors who want to gain high profits. But the PATSOS forecast model must work with high "hit rates" to make investors possible to follow mentioned signs above. In this study, the PATSOS model has 54\% accurate forecast rates (hit rate). So, it should be noted that mostly PATSOS gives accurate signals for investing. 


\section{Conclusion}

Today, many people prefer fast and reliable financial transaction mechanisms as a result of technological innovations. Digital currencies such as Bitcoin and Ethereum, as well as the blockchain system, are examples of this. Currently, cryptocurrencies' estimated market capitalization has already exceeded the hundreds of billions of dollars level. Initially, cryptocurrencies were viewed solely as a means of transferring money, but they have since emerged as a viable investment opportunity (Jay et al., 2020). Notably, according to the Fortune Business Insight report (2020) the worldwide cryptocurrency market size was USD 754.0 million in 2019 and is expected to reach USD 1,758.0 million by 2027.

Since cryptocurrencies have recently gained so much popularity, forecasting efforts of their pricing have newly become a charming issue for both researchers and investors. Several researchers have tried to forecast various cryptocurrencies' prices via computational intelligence models in the literature. And there are much fewer studies that practice for finding trends of Monero prices. To the best of the authors' knowledge, no study uses the PATSOS method to estimate Monero prices and trends which we use in our analysis. This research may be considered as the first to use the PATSOS model to forecast Monero pricing and trends.

According to our analysis results, when specified inputs are served, the PATSOS model has forecasted future Monero prices with very little error rate $(0,00305)$. In other words, the PATSOS model produced accurate and consistent forecasting results following the real data. These findings clearly indicate the success of the PATSOS forecasting model.

On the other hand, with the help of the consistent "buy" and "sell" signals which the PATSOS system produced, the investors can resist to price volatiles and get rid of a big amount of money loses. According to the analysis results, the PATSOS model gives accurate trading signals with a $54 \%$ accuracy rate. It should also be noted that investors have a possibility to gain bigger profits when they get signals of "sell" and allocates their assets to other logical choices.

The cryptocurrency market has high volatility that makes it impossible to gain high profits by calculating price movements. This assertion is in accordance with the famous "efficient market hypothesis (EMH)" that is introduced by Fama (1965) saying price movements are random and unpredictable in the efficient market. But the PATSOS model due to its' closedloop controller feedback mechanism, bears against the weak form of EMH, indicating that the historical data has the ability to forecast Monero prices. In other words, the PATSOS model mechanism can handle uncertainties related to the dynamic behavior of the Monero prices.

In future studies, to improve the accessibility of the PATSOS model by the investors, a more user-friendly environment can be designed. Furthermore, other neuro-fuzzy forecasting models can be added to the benchmark PATSOS model. 


\section{References}

Aggarwal, D.; Chandrasekaran, S.; Annamalai, B. (2020), "A Complete Empirical Ensemble Mode Decomposition and Support Vector Machine-Based Approach to Predict Bitcoin Prices", Journal of Behavioral and Experimental Finance, Vol. 27, No. 2020: 1-12.

Akyildirim, E.; Goncu, A.; Sensoy, A. (2021), "Prediction of Cryptocurrency Returns Using Machine Learning", Annals of Operations Research, Vol. 297, No. 1: 3-36.

Altan, A.; Karasu, S.; Bekiros, S. (2019), "Digital Currency Forecasting with Chaotic Meta-Heuristic Bio-Inspired Signal Processing Techniques", Chaos, Solitons \& Fractals, Vol. 126, No. 2019: 325-336.

Atsalakis, G. S.; Valavanis, K. P. (2009), "Forecasting Stock Market Short-Term Trends Using A NeuroFuzzy Based Methodology", Expert Systems with Applications, Vol. 36, No. 7: 10696-10707.

Atsalakis, G. S.; Frantzis, D.; Zopounidis, C. (2015), "Energy's Exports Forecasting by a Neuro-Fuzzy Controller", Energy Systems, Vol. 6, No. 2: 249-267.

Atsalakis, G. S. (2016), "Using Computational Intelligence to Forecast Carbon Prices", Applied Soft Computing Journal, Vol. 43, No. 2016: 107-116.

Atsalakis, G. S.; Protopapadakis, E. E.; Valavanis, K. P. (2016a), "Stock Trend Forecasting in Turbulent Market Periods Using Neuro-Fuzzy Systems", Operational Research, Vol. 16, No. 2: 245-269.

Atsalakis, G. S.; Frantzis, D.; Zopounidis, C. (2016b), "Commodities' Price Trend Forecasting by A Neuro-Fuzzy Controller", Energy Systems, Vol. 7, No. 1: 73-102.

Atsalakis, G. S.; Atsalakis, I. G.; Pasiouras, F.; Zopounidis, C. (2019), "Bitcoin Price Forecasting with Neuro-Fuzzy Techniques", European Journal of Operational Research, Vol. 276, No. 2: 770-780.

Chen, W.; Xu, H.; Jia, L.; Gao, Y. (2021), "Machine Learning Model for Bitcoin Exchange Rate Prediction Using Economic and Technology Determinants", International Journal of Forecasting, Vol. 37, No. 1: 28-43.

Chowdhury, R.; Rahman, M. A.; Rahman, M. S.; Mahdy, M. R. C. (2020), "An Approach to Predict and Forecast the Price of Constituents and Index of Cryptocurrency Using Machine Learning", Physica A: Statistical Mechanics and its Applications, Vol. 551, No.2020: 1-17.

Fama, E. F. (1965), "The Behavior of Stock-Market Prices", The Journal of Business, Vol. 38 No. 1: $34-$ 105.

Fortune Business Insight (2020), https://www.fortunebusinessinsights.com/industryreports/cryptocurrency-market-100149 (Accessed: 31.05.2021).

Guiu, J. G.; i Ribé, E. G.; i Mansilla, E. B.; i Fàbrega, X. L. (1999). "Automatic Diagnosis with Genetic Algorithms and Case-Based Reasoning", Artificial Intelligence in Engineering, Vol. 13, No. 4: 367-372.

Jay, P.; Kalariya, V.; Parmar, P.; Tanwar, S.; Kumar, N.; Alazab, M. (2020), "Stochastic Neural Networks for Cryptocurrency Price Prediction", IEEE Access, Vol. 8, No. 2020: 82804-82818.

Ji, S.; Kim, J.; Im, H. (2019), "A Comparative Study of Bitcoin Price Prediction Using Deep Learning", Mathematics, Vol. 7, No. 10: 898.

Karasu, S.; Altan, A.; Saraç, Z.; Hacıoğlu, R. (2018), "Prediction of Bitcoin Prices with Machine Learning Methods Using Time Series Data", https://ieeexplore.ieee.org/abstract/document/8404760, (Accessed: 03.05.2021).

Kristjanpoller, W.; Minutolo, M. C. (2018), "A Hybrid Volatility Forecasting Framework Integrating GARCH, Artificial Neural Network, Technical Analysis and Principal Components Analysis", Expert Systems with Applications, Vol. 109, No.2018: 1-11.

Lahmiri, S.; Bekiros, S. (2019), "Cryptocurrency Forecasting with Deep Learning Chaotic Neural Networks", Chaos, Solitons \& Fractals, Vol. 118, No. 2019: 35-40.

Liu, M.; Li, G.; Li, J.; Zhu, X.; Yao, Y. (2020), "Forecasting the Price of Bitcoin Using Deep Learning", Finance Research Letters, Article in Press, 101755. 
McNally, S.; Roche, J.; Caton, S. (2018), "Predicting the Price of Bitcoin Using Machine Learning", https://ieeexplore.ieee.org/abstract/document/8374483, (Accessed: 03.05.2021)

Nakamoto, S. (2009), "Bitcoin: Peer-to-Peer Electronic Cash System". https://nakamotoinstitute.org/bitcoin/, (Accessed: 01.05.2021).

Nakano, M.; Takahashi, A.; Takahashi, S. (2018), "Bitcoin Technical Trading with Artificial Neural Network", Physica A: Statistical Mechanics and its Applications, Vol. 510, No. 2018: 587-609.

Norgaard, M.; Ravnm, O.; Poulsen, N. K. (2003), Neural Networks for Modelling and Control Dynamic Systems, London: Springer.

Oppenheim, D.; Shani, G. (2017). "Potato Disease Classification Using Convolution Neural Networks". Advances in Animal Biosciences: Precision Agriculture (ECPA), Vol. 8, No. 2: 244-249.

Patel, M. M.; Tanwar, S.; Gupta, R.; Kumar, N. (2020), "A Deep Learning-Based Cryptocurrency Price Prediction Scheme for Financial Institutions", Journal of Information Security and Applications, Vol. 55, No. 2020: 1-12.

Pintelas, E.; Livieris, I. E.; Stavroyiannis, S.; Kotsilieris, T.; Pintelas, P. (2020), "Investigating the problem of cryptocurrency price prediction: a deep learning approach". In: Maglogiannis I., lliadis L., Pimenidis E. (eds) Artificial Intelligence Applications and Innovations. AIAI 2020. IFIP Advances in Information and Communication Technology, Springer, vol 584: 99-110.

Poongodi, M.; Sharma, A.; Vijayakumar, V.; Bhardwaj, V.; Sharma, A. P.; Iqbal, R.; Kumar, R. (2020), "Prediction of The Price of Ethereum Blockchain Cryptocurrency in an Industrial Finance System", Computers \& Electrical Engineering, Vol. 81, No. 2020: 1-12.

Sun, X.; Liu, M.; Sima, Z. (2020), "A Novel Cryptocurrency Price Trend Forecasting Model Based on LightGBM", Finance Research Letters, Vol. 32, No. 2020: 1-6.

Urfalığlu, F.; Tanrıverdi, i. (2018), "Anfis ve Regresyon Analizi ile Enflasyon Tahmini ve Karşılaştırması", Social Sciences Research Journal, Vol. 7, No. 3: 120-141.

Yücel, A.; Güneri, A. F. (2010), "Application of Adaptive Neuro Fuzzy Inference System to Supplier Selection Problem", Journal of Engineering and Natural Sciences, Vol. 28, No. 212: 224-234.

www.coinmarketcap.com, (Accessed: 07.04.2021) 